\title{
Aproveitamento de plântulas de porta-enxertos cítrico oriundas do desbaste e seu desenvolvimento vegetativo inicial
}

\author{
Utilization of rootstock citrus seedlings deriving of thinning and its initial vegetative development
}

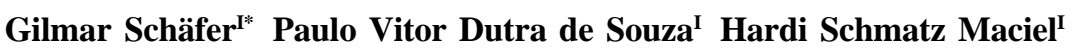 \\ Mário Luís Fochesato ${ }^{\mathrm{I}}$
}

\section{RESUMO}

Avaliou-se o desenvolvimento vegetativo inicial de porta-enxertos cítricos cultivados em casa de vegetação, por meio de semeadura e de repicagem de raiz nua. $O$ experimento foi conduzido em casa de vegetação, na Estação Experimental Agronômica da UFRGS, em Eldorado do Sul, RS, a partir do mês de setembro de 2003, afim de testar a viabilidade de aproveitamento de plântulas oriundas do desbaste. O delineamento experimental adotado foi o de blocos casualizados, com quatro repetições, em esquema de parcela subdividida e cada subparcela constituída por 22 tubetes. Nas parcelas principais foram testados dois sistemas de propagação: semeadura e repicagem no momento do desbaste. Nas subparcelas foram testados três porta-enxertos cítricos: Trifoliata (Poncirus trifoliata [L.] Raf.), citrangeiro "C37” (P. trifoliata $x$ Citrus sinensis [L.] Osbeck.) e limoeiro "Cravo" (C. limonia Osbeck.). A semeadura foi realizada em tubetes cônicos de polietileno preto (capacidade de $120 \mathrm{~cm}^{3}$ ), com duas a três sementes por tubete. A repicagem foi feita no momento do desbaste da bandeja semeada quando as plântulas estavam, em média, com duas a quatro folhas. Os resultados demonstraram que há viabilidade de aproveitamento das plântulas resultantes do desbaste, sem que ocorra diferenças no desenvolvimento vegetativo. Além disso, foi observado que o porta-enxerto "C37" apresentou um vigor inicial maior que o Trifoliata e o limoeiro “Cravo".

Palavras-chave: propagação, cultivo protegido, Poncirus trifoliata, Citrus limonia.

\section{ABSTRACT}

The initial vegetative growth of citrus seedling rootstocks was evaluated by means of sowing and transplantation of bare-root seedling. The experiment was conduced in September 2003 in greenhouse conditions in the Estação Experimental Agronômica/UFRGS in Eldorado do Sul, Brazil. The objective of this study was to test the viability of use of seedlings deriving from thinning. The experiment was in randomized blocks with four replications in a split plot design and each sub-plot consisted of 22 tubs. In the main plot were tested two propagation systems: sowing and transplantation at the thinning moment. In sub-plots were tested three citrus rootstocks: Trifoliate orange (Poncirus trifoliata [ L. ] Raf.); 'C37' citrange (P. trifoliata x Citrus sinensis [ L. ] Osbeck.), and 'Rangpur' lime (C. limonia Osbeck.). The sowing was carried in conical tubs of black polyethylene (capacity of $120 \mathrm{~cm}^{3}$ ) with two to three seeds in each tub. Transplantation was made at the thinning moment, when the seedlings had, in average, two to four leaves. The results demonstrate that it is possible to use seedlings resulting from thinning, without differences in the vegetative development comparatively to sowing. The 'C37' citrus rootstock presents a larger initial vigor when compared to the other citrus rootstocks tested.

Key words: propagation, greenhouse, Poncirus trifoliata, Citrus limonia.

\section{INTRODUÇÃO}

Entre as diversas culturas agrícolas no Brasil, a citricultura ocupa lugar de destaque, principalmente pelo valor de exportação da fruta e, não menos importante, pela sua importância social, gerando renda à pequena propriedade e um grande número de empregos. Dos diversos elos da cadeia produtiva, o produtor de mudas (viveirista) é quem vem sofrendo

'Programa de Pós-graduação em Fitotecnia, faculdade de Agronomia, Departamento de Horticultura e Silvicultura, Universidade Federal do Rio Grande do Sul (UFRGS). Av. Bento Gonçalves, 7712, 91501-970, Porto Alegre, RS, Brasil. E-mail: gilmarschafer@hotmail.com.*Autor para correspondência. 
as maiores mudanças nos últimos tempos, basicamente impulsionadas pela necessidade de produzir mudas genética e fitossanitariamente garantidas. Como conseqüência, o tradicional viveiro de campo, em alguns Estados brasileiros, já foi totalmente abolido.

Em sistemas de produção de mudas de citros envasadas, já utilizados em vários países, inclusive no Brasil, no Estado de São Paulo, pode-se evitar a presença de patógenos, a partir do isolamento da sementeira e do viveiro, pelo tratamento do substrato e da água de irrigação. No Rio Grande do Sul, a produção de mudas cítricas ainda, em quase a sua totalidade, é feita à campo, em pequenas propriedades, produzindo, em média, 15 mil mudas (SCHÄFER, 2000). Para 2007, já está prevista a passagem da produção à campo para um sistema em ambiente protegido, com normas específicas.

$\mathrm{O}$ atual sistema prevê a semeadura do portaenxerto em canteiros à campo (sementeira), onde esse é cuidado por um ano para ser repicado ao viveiro no inverno seguinte. A repicagem é feita selecionando-se os porta-enxertos por tamanho, descartando-se as mudas menores ou com sistema radicular defeituoso e fazendo-se uma poda das raízes e um desponte do caule nas demais (KOLLER, 1994).

No sistema de produção de mudas cítricas em ambiente protegido, nesta primeira etapa (sementeira), são utilizadas, com grande vantagens, bandejas de isopor ou recipientes de plástico de forma cônica (tubetes), todos vazados na parte basal e fixados em bancadas suspensas afastadas da superfície do solo. Como meio de cultivo, são utilizados substratos, livre de solos, com características físicas, químicas e biológicas adequadas (SCHMITZ, 1998).

Na semeadura, normalmente, são utilizadas de duas a três sementes por tubetes, sendo que normalmente mais de uma semente germina e, muitas vezes, emergem mais de uma plântula por semente, pois estas são poliembriônicas. A partir disso, existe a necessidade de ser feito um desbaste, normalmente realizado quando as plântulas possuem de duas a três folhas, deixando-se apenas uma por tubete, a de maior vigor e a mais central (SCHÄFER, 2000).

Geralmente são descartadas plantas pequenas e defeituosas, mas também muitas plantas com bom vigor e morfologicamente perfeitas. A partir da necessidade de aproveitar ao máximo o material propagativo utilizado, existe a possibilidade de aproveitar muitas plântulas que seriam descartadas no desbaste, repicando aquelas vigorosas e sem defeitos para novos recipientes, ou para aqueles onde não germinou nenhuma semente. Em função dessa nova prática, a pesquisa deve esclarecer a influência da repicagem dos porta-enxertos de raiz nua, comparativamente à de torrão, sobre o desenvolvimento vegetativo e a morfologia radicular dos mesmos.

O objetivo deste trabalho foi avaliar o desenvolvimento vegetativo inicial de porta-enxertos cítricos, cultivados em casa de vegetação, por meio de semeadura e de repicagem de raiz nua.

\section{MATERIAL E MÉTODOS}

O experimento foi conduzido em casa de vegetação, na Estação Experimental Agronômica da Universidade Federal do Rio Grande do Sul (EEA/ UFRGS), situada em Eldorado do Sul, RS, a partir do mês de setembro de 2003. O delineamento experimental adotado foi o de blocos casualizados, com quatro blocos, em esquema de parcelas subdivididas e cada sub-parcela constituída por 22 tubetes. Nas parcelas principais testou-se os dois sistemas de propagação: semeadura e repicagem no momento do desbaste. Nas subparcelas foram testados três porta-enxertos cítricos: Trifoliata (Poncirus trifoliata [L.] Raf.), citrangeiro "C37” (P. trifoliata x Citrus sinensis [L.] Osbeck.) e limoeiro “Cravo" (C. limonia Osbeck.).

A semeadura foi realizada em tubetes cônicos de polietileno preto (capacidade de $120 \mathrm{~cm}^{3}$ ), vazados na parte basal, fixados em bancadas metálicas, utilizando-se o substrato comercial Plantmax Citrus ${ }^{\circledR}$, com duas a três sementes por tubete, submetidos à irrigação por microaspersão, variando de dez a trinta minutos diários, conforme a demanda hídrica.

Após a emergência, quando as plântulas estavam, em média, com duas a quatro folhas (64 dias após a emergência), fez-se um desbaste da bandeja semeada, deixando-se apenas uma plântula por tubete, aquela maior e mais central. As plântulas descartadas foram acondicionadas em um balde plástico com água, sendo que as mais vigorosas e com sistema radicular perfeito foram selecionadas para repicagem para tubetes de volume semelhante àqueles semeados diretamente. Antecedendo a repicagem, fez-se uma poda de raízes, retirando-se em torno de $1 / 3$ a $2 / 3$ de seu comprimento e, com auxílio de uma haste, abriu-se um orifício no substrato introduzindo as raízes e pressionando o substrato para proporcionar bom contato com as raízes, evitando, assim, a formação de bolsões de ar. Em seguida, fez-se uma rega manual. Empregou-se o mesmo substrato citado anteriormente.

Como adubação de cobertura, de acordo com VICHIATO et al. (1998), foi utilizada 0,1g de N por planta, aplicada duas vezes, aos 117 e 180 dias após a semeadura, diluído em água a um volume de cinco $\mathrm{mL}$ por planta para cada aplicação. 
As seguintes características foram avaliadas: percentual de sobrevivência das plântulas repicadas, determinação do vigor, por meio de: diâmetro da haste, ao nível do colo, em mm, comprimento da parte aérea, medida do colo até o ápice da haste, em $\mathrm{cm}$, área foliar por plântula, em $\mathrm{cm}^{2}$, medida através da passagem das folhas por um medidor de área foliar de marca LI-Cor, modelo LI - 3100, matéria seca da raiz principal e secundária, parte aérea (haste e folhas) e total (raiz + parte aérea), em gramas, obtido pela secagem à estufa, com temperatura de $65^{\circ} \mathrm{C}$, até peso constante; e determinação do conteúdo de $\mathrm{N}$ (total), $\mathrm{P}, \mathrm{K}, \mathrm{Ca}$ e $\mathrm{Mg}$ nas folhas, segundo metodologia descrita por TEDESCO et al. (1995), realizada no Laboratório de Solos e Tecidos do Departamento de Solos da Faculdade de Agronomia da UFRGS.

As médias foram submetidas à análise de variância e comparadas pelo teste de Duncan em nível de 5\% de significância. A variável crescimento em altura das plantas no decorrer do experimento foi submetida à análise de regressão em esquema de parcela subdividida no tempo.

\section{RESULTADOS E DISCUSSÃO}

O percentual de sobrevivência das plântulas repicadas foi extremamente elevado (99,62\%), mesmo tendo sido realizada em dia com temperaturas elevadas (30 $\mathrm{C})$.

Na tabela 1, estão descritos os dados referentes à altura final dos porta-enxertos cultivados nos dois métodos estudados. Observa-se que houve interação para o efeito sistema de propagação e portaenxertos como conseqüência do comportamento do limoeiro "Cravo", que apresentou uma menor altura em relação ao Trifoliata, na semeadura direta, e não diferiu do mesmo, quando repicado. Mesmo assim não houve

Tabela 1 - Altura final de porta-enxertos cítricos, submetidos a dois sistemas de propagação, cultivados em tubetes e casa de vegetação. EEA/UFRGS, Eldorado do Sul, 2004.

\begin{tabular}{lccc}
\hline & -----Altura da planta (cm)----- \\
Sistema de propagação & -----Porta-enxerto----- \\
& “C37” & Trifoliata & “Cravo” \\
& 20,98 a B ${ }^{1}$ & 26,17 a A & 21,66 a B \\
Semeadura direta & 21,33 a B & 24,68 a A & 24,43 a A \\
Repicagem & & 7,60 & \\
CV (\%) - Sistema de irrigação & & 5,13 & \\
CV (\%) - Porta-enxerto & & & \\
\hline
\end{tabular}

${ }^{1}$ Médias seguidas por letras minúsculas distintas, na coluna e por letras maiúsculas distintas na linha, diferem entre si, pelo teste de Duncan, em nível de 5\% de significância. diferenças significativas no desenvolvimento em altura dos porta-enxertos nos dois sistemas de propagação. O Trifoliata sobressaiu-se aos demais, principalmente no sistema de propagação por semeadura, conforme já descrito por outros autores (SCHÄFER, 2000 e SCHÄFER et al., 2000), que confirmam o rápido crescimento inicial do Trifoliata, mesmo sendo um porta-enxerto que induz um efeito ananizante nas cultivares copa. O “C37” teve um desenvolvimento menor nos dois sistemas, quando comparado com o Trifoliata.

O desenvolvimento em altura dos portaenxertos ao longo do tempo teve uma tendência linear, sem diferenças significativas entre os dois sistemas de propagação (Figura 1A). Observou-se que os porta-enxertos já aos 83 dias após a semeadura (DAS) estavam, em média, com sete centímetros de altura, atingindo, aos 225DAS, em média, $23 \mathrm{~cm}$. O comportamento dos três porta-enxertos, em geral, manteve a mesma tendência linear crescente, com o Trifoliata tendo crescimento maior logo no início, mantendo-a até o final (Figura 1B). Esses resultados corroboram as afirmações feitas em experimentos anteriores de que o mesmo tem um desenvolvimento inicial muito rápido em altura, podendo chegar a vários centímetros em semanas. Observa-se que o "Cravo" teve um desenvolvimento menor no início, mas conseguiu igualar-se ao "C37" no final do experimento.

Em valores absolutos, a altura média de planta encontrada neste experimento foi bem superior à encontrada em outros trabalhos (CARVALHO e SOUZA, 1996; VICHIATO et al., 1998; SCHMITZ, 1998; SCHÄFER, 2000). Basicamente, as diferenças para esse maior crescimento podem ser explicadas pelo fato de que SCHÄFER (2000) realizou seu trabalho no inverno, com baixas temperaturas, o que limitou o desenvolvimento dos porta-enxertos. Os demais autores (CARVALHO \& SOUZA, 1996; VICHIATO et al., 1998; SCHMITZ, 1998) avaliaram precocemente seus experimentos e, como pode ser verificado na figura 1 , mesmo até os 225 DAS não houve estabilização do crescimento dos porta-enxertos, indicando que este poderia seguir desenvolvendo-se nos tubetes.

Quanto à área foliar (Tabela 2), observou-se que os porta-enxertos “C37” e Trifoliata não apresentaram diferenças significativas nos dois sistemas de propagação, mas o limoeiro "Cravo" obteve maiores índices quando repicado. Esses maiores índices são decorrentes de um pequeno acréscimo no número de folhas e de um maior crescimento da área foliar por folha. 


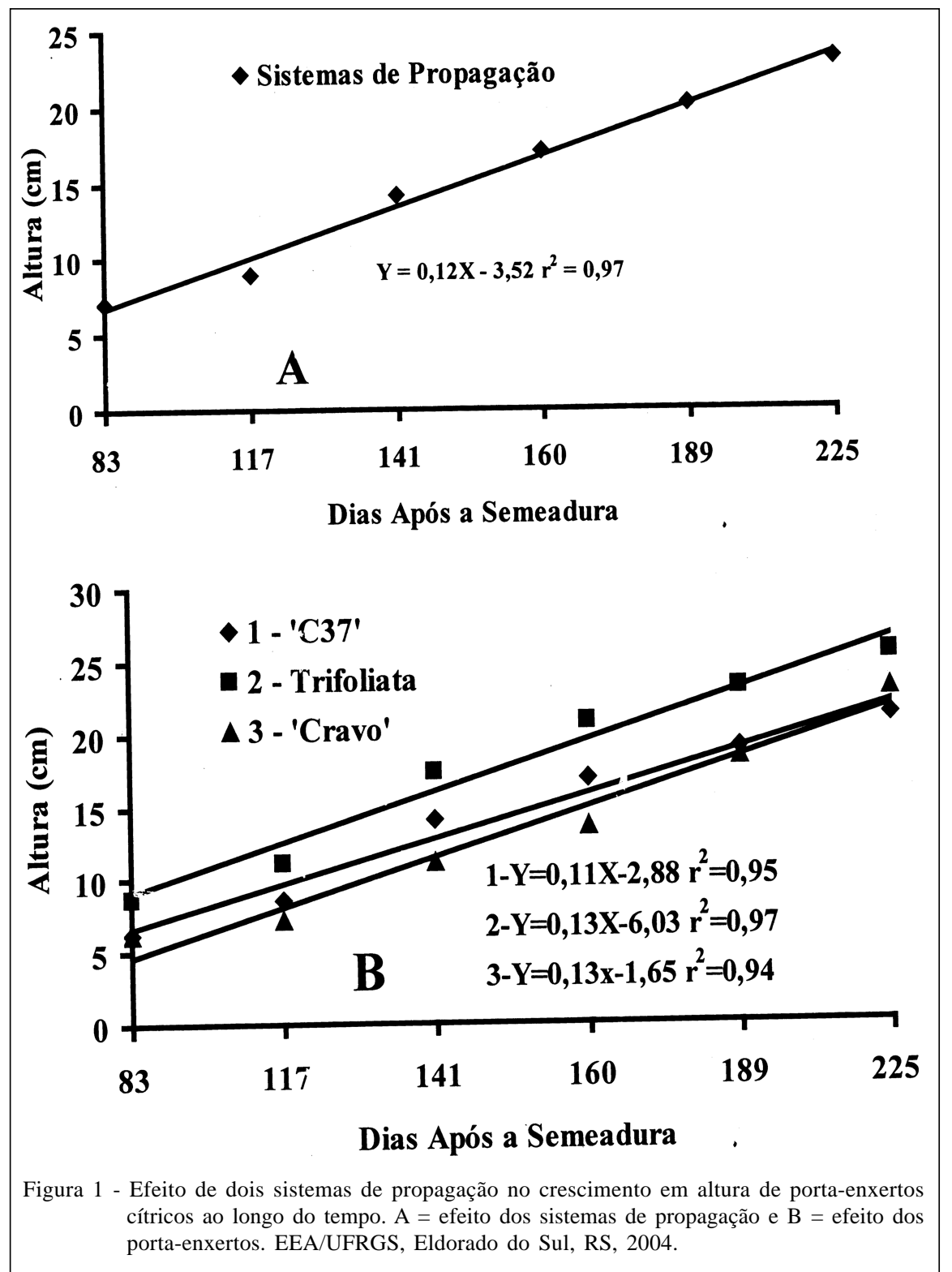

A diferença fenotípica entre os portaenxertos estudados é a principal responsável pela variação no número de folhas, na área foliar e na área foliar por folha, sendo que o "Cravo" possui os maiores índices de área foliar, seguido pelo “C37” e o Trifoliata. Mesmo assim, o "C37” igualou-se na área foliar por folha, o que deve ter influenciado as características de crescimento deste.

Apesar de não ter havido diferenças entre os métodos de propagação em altura de plantas (Tabela 1), o limoeiro "Cravo" igualou-se em tamanho ao Trifoliata no tratamento de repicagem. Isso pode ter ocorrido pelo fato de o mesmo possuir maior número de folhas e maior área foliar nesse tratamento, o que incrementou o seu desenvolvimento (Tabela 2).

Na tabela 3 são listados os índices de massa seca e o diâmetro. Observa-se que, como ocorreu para as demais características de desenvolvimento vegetativo, o sistema de propagação não afetou o acúmulo de massa seca, nem o diâmetro dos portaenxertos estudados. Quanto ao comportamento dos porta-enxertos estudados, observa-se que o "C37” foi o que apresentou maior acúmulo de massa seca e maior diâmetro final da haste. Estas características são importantes no futuro desenvolvimento do portaenxerto na fase de viveiro, pois, se o mesmo mantiver 
Tabela 2 - Área foliar de porta-enxertos cítricos, cultivados em dois sistemas de propagação em casa de vegetação. EEA/UFRGS, Eldorado do Sul, 2004.

\begin{tabular}{|c|c|c|c|}
\hline \multirow{3}{*}{ Sistema de Propagação } & \multicolumn{3}{|c|}{-----------------------------Área foliar $\left(\mathrm{cm}^{2} \mathrm{planta}^{-1}\right)$--------------------------. } \\
\hline & \multicolumn{3}{|c|}{ 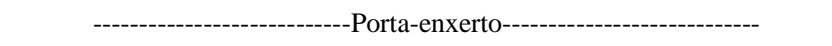 } \\
\hline & “C37” & Trifoliata & “Cravo” \\
\hline Semeadura direta & 47,74 a B ${ }^{1}$ & 22,13 a $C$ & 74,99 b A \\
\hline Repicagem & 52,52 a B & 22,87 a C & 96,98 a $A$ \\
\hline CV (\%) - Sistema de propagação & & 10,37 & \\
\hline CV (\%) - Porta-enxerto & & 9,88 & \\
\hline
\end{tabular}

${ }^{1}$ Médias seguidas por letras minúsculas distintas, na coluna e por letras maiúsculas distintas na linha, diferem entre si, pelo teste de Duncan, em nível de $5 \%$ de significância.

esses índices, provavelmente acelerará seu desenvolvimento e antecipará a enxertia, por ter maior diâmetro do caule, fator que é determinante para realizar essa prática. Estes dados colaboram para facilitar a diversificação de porta-enxertos, na medida que se juntam às características favoráveis dos citranges já conhecidas, no pomar ao bom desenvolvimento vegetativo desse no viveiro (SOUZA et al., 1992; SCHÄFER et al., 2001).

Não houve interação significativa entre sistemas de propagação e porta-enxertos para teor de macronutrientes (Tabela 4). Tampouco foram encontradas diferenças significativas para os teores de nitrogênio, potássio e magnésio no fator sistema de propagação. Segundo padrões da recomendação da COMISSÃO DE FERTILIDADE DO SOLO (2000), o teor de nitrogênio presente nesses porta-enxertos, referente aos sistemas de propagação, é considerado excessivo, enquanto que o fósforo é considerado alto e, o potássio excessivo, o cálcio e o magnésio, baixos.

Os teores de nitrogênio na massa seca das folhas foi bem superior ao recomendado, que é de 23 a $27 \mathrm{~g} \mathrm{~kg}^{-1}$, configurando-se como excessivo nos três porta-enxertos estudados. O Trifoliata foi mais efetivo na absorção de $\mathrm{P}$, diferindo estatisticamente dos demais. No entanto, apesar de estes terem teores menores, são considerados satisfatórios na planta. Os teores de potássio são considerados altos na planta. A maior absorção de $\mathrm{K}$ pelas plântulas deve ter limitado a absorção de Ca e Mg, devido ao efeito antagônico entre K/Ca e K/Mg. Apesar de serem constatadas diferenças estatísticas nos níveis de cálcio, estas são considerados baixas e deficientes, sendo que isso também ocorre para o magnésio.

Tabela 3 - Massa seca total de raiz (MSTR), de raiz principal (MSRP), de raiz secundária (MSRS), da relação MSRP/MSRS, da parte aérea total (MSAT) e total da planta (MST) e diâmetro da haste de porta-enxertos cítricos, cultivados em dois sistemas de propagação em casa de vegetação. EEA/UFRGS, Eldorado do Sul, 2004.

\begin{tabular}{|c|c|c|c|c|c|c|c|c|}
\hline \multicolumn{2}{|l|}{ Tratamento } & MSTR & MSRP & MSRS & MSRP/MSRS & MSAT & MST & \multirow{2}{*}{$\begin{array}{c}\text { Diâmetro } \\
\text { mm }\end{array}$} \\
\hline \multirow{2}{*}{ Sistema de propagação } & Semeadura direta & 0,82 & 0,47 & 0,35 & 1,37 & 1,12 & 1,94 & \\
\hline & Repicagem & 0,76 & 0,45 & 0,31 & 1,50 & 1,21 & 1,97 & 3,46 \\
\hline \multicolumn{2}{|c|}{ CV (\%) } & 6,37 & 6,43 & 10,61 & 8,38 & 9,79 & 8,35 & 3,62 \\
\hline \multirow{3}{*}{ Porta-enxerto } & “C37” & $0,95 a^{1}$ & $0,60 \mathrm{a}$ & 0,35 a & 1,75 a & 1,26 a & $2,20 \mathrm{a}$ & 3,95 a \\
\hline & Trifoliata & $0,74 \mathrm{~b}$ & $0,36 \mathrm{~b}$ & 0,38 a & 0,97 c & $0,99 \mathrm{~b}$ & $1,74 \mathrm{~b}$ & $3,31 \mathrm{~b}$ \\
\hline & “Cravo” & $0,68 \mathrm{~b}$ & $0,41 \mathrm{~b}$ & $0,27 \mathrm{~b}$ & $1,59 \mathrm{~b}$ & $1,24 \mathrm{a}$ & $1,91 \mathrm{ab}$ & $3,04 \mathrm{~b}$ \\
\hline \multicolumn{2}{|c|}{ CV (\%) } & 18,24 & 19,25 & 17,57 & 6,80 & 12,01 & 14,02 & 7,41 \\
\hline
\end{tabular}

${ }^{1}$ Médias seguidas por letras minúsculas distintas, na coluna, diferem entre si, pelo teste de Duncan, em nível de 5\% de significância.

Ciência Rural, v.38, n.6, set, 2008. 
Tabela 4 - Teores de macronutrientes presentes nas folhas de porta-enxertos cítricos, cultivados em dois sistemas de propagação e em casa de vegetação. EEA/UFRGS, Eldorado do Sul, 2004.

\begin{tabular}{|c|c|c|c|c|c|c|}
\hline \multirow{2}{*}{ Tratamento } & & \multicolumn{5}{|c|}{----------------Conteúdo nutricional g kg-1 na matéria seca total------------------ } \\
\hline & & Nitrogênio & Fósforo & Potássio & Cálcio & Magnésio \\
\hline \multirow{2}{*}{ Sistema de propagação } & Semeadas & 33,14 & $1,57 \mathrm{~b}$ & 22,12 & 18,26 a & 2,68 \\
\hline & Repicadas & 30,47 & 1,69 a & 20,74 & $14,88 \mathrm{~b}$ & 2,56 \\
\hline \multirow[t]{2}{*}{ CV (\%) } & & 5,96 & 3,21 & 4,76 & 1,83 & 4,11 \\
\hline & “C37” & 31,43 & $1,51 b^{1}$ & 21,33 & $18,01 \mathrm{a}$ & $2,75 \mathrm{a}$ \\
\hline \multirow[t]{2}{*}{ Porta-enxerto } & Trifoliata & 32,72 & $1,81 \mathrm{a}$ & 21,25 & $16,99 \mathrm{~b}$ & $2,83 \mathrm{a}$ \\
\hline & “Cravo” & 31,28 & $1,56 \mathrm{~b}$ & 21,72 & $14,71 \mathrm{c}$ & $2,29 \mathrm{~b}$ \\
\hline \multicolumn{2}{|c|}{ CV (\%) } & 9,00 & 8,74 & 9,48 & 3,89 & 8,01 \\
\hline
\end{tabular}

${ }^{1}$ Médias seguidas por letras minúsculas distintas, na coluna, diferem entre si, pelo teste de Duncan, em nível de 5\% de significância.

\section{CONCLUSÕES}

Na produção de porta-enxertos em tubetes e casa de vegetação, há viabilidade de aproveitamento daqueles resultantes do desbaste, repicando-os quando apresentam duas a quatro folhas. O portaenxerto "C37" apresenta um vigor inicial maior que o Trifoliata e o limoeiro "Cravo".

\section{REFERÊNCIAS}

CARVALHO, S.A. de; SOUZA, M. de. Doses e freqüência de aplicação de nitrato de potássio no crescimento do limoeiro "Cravo" e da tangerineira "Cleópatra” em bandejas. Pesquisa Agropecuária Brasileira, Brasília, v.31, n.11, p.815-822, 1996.

COMISSÃO DE FERTILIDADE DO SOLO - RS e SC. Recomendações de adubação e de calagem para os estados do Rio Grande do Sul e de Santa Catarina. 3.ed. Passo Fundo: SBCS - Núcleo Regional Sul, 2000. $223 p$.

KOLLER, O.C. Citricultura: laranja, limão e tangerina. Porto Alegre: Rigel, 1994. 446p.

SCHAFER, G. et al. Porta-enxertos utilizados na citricultura. Ciência Rural, v.31, n.4, p.723-733, 2001.
SCHÄFER, G. Caracterização molecular, diagnóstico e avaliação de porta-enxertos na citricultura gaúcha. 2000. 81f. Dissertação (Mestrado) Programa de Pós-graduação em Fitotecnia, Faculdade de Agronomia, Universidade Federal do Rio Grande do Sul, Porto Alegre.

SCHÄFER, G. et al. Desenvolvimento vegetativo de portaenxertos de citros cultivados em diversos substratos. In: ENCONTRO NACIONAL SOBRE SUBSTRATOS PARA PLANTAS, 2., 2000, Florianópolis. Anais... Florianópolis, 2000. p.56-57.

SCHMITZ, J.A.K. Cultivo de Poncirus trifoliata (L.) Raf. em recepientes: influência de substratos e de fungos micorrízicos arbusculares. 1998. 144f. Dissertação (Mestrado em Fitotecnia) - Programa de Pós-graduação em Fitotecnia, Faculdade de Agronomia, Universidade Federal do Rio Grande do Sul, Porto Alegre.

SOUZA, E.L.S. et al. Comportamento do Tangor "Murcote" em 12 porta-enxertos no Rio Grande do Sul. Revista Brasileira de Fruticultura, Cruz das Almas, v.14, n.3, p.105-112, 1992.

TEDESCO, M.J. et al. Análises de solo, plantas e outros materiais. 2.ed. Porto Alegre: Departamento de Solos da UFRGS, 1995. 174p. (Boletim Técnico de Solos, 5).

VICHIATO, M. et al. Desenvolvimento e nutrição mineral da tangerineira cleópatra fertilizada com superfosfato simples e nitrato de amônio em tubetes até a repicagem. Ciência e Agrotecnologia, Lavras, v.22, n.1, p.30-41, 1998. 